\title{
Origin, Phylogeny and Natural Behavior of Mice: What is Their Influence on Welfare During their Maintenance in the House Facilities?
}

\author{
Susana Melo da Costa ${ }^{1}$, Maria Inês Doria Rossi ${ }^{2}$, Alexandre Andrade Evagelista ${ }^{3}$ and Gabriel \\ Oliveira $^{3 *}$
}

${ }^{1}$ Federal University of Rio de Janeiro, Brazil

${ }^{2}$ Institute of Science and Technology in Biomodel, Brazil

${ }^{3}$ Department of Cell Biology, Oswaldo Cruz Institute, Brazil

*Corresponding author: Gabriel Melo de Oliveira, Department of Cell Biology, Instituto Osvaldo Cruz, Rio de Janeiro, Brazil.

To Cite This Article: Gabriel Melo de Oliveira. Origin, Phylogeny and Natural Behavior of Mice: What is Their Influence on Welfare During their Maintenance in the House Facilities?. Am J Biomed Sci \& Res. 2019 - 5(5). AJBSR.MS.ID.000946. DOI: 10.34297/AJBSR.2019.05.000946.

Received: 眥 October 02, 2019; Published: 此 October 11, 2019

\begin{abstract}
The mouse is the species most used for didactic and scientific purposes. Given the ethical principles, Brazil's legislation and normatives, it is recommended that the welfare of mice in the laboratory be linked to the promotion of conditions in which the animal can express its natural behavior. However, in the literature, information on the natural behavior of mice is limited. Thus, the objective of this work was to conduct a study on several genealogical and phylogenetic aspects. Origin of the mouse was 14 million years ago by rodents that inhabited the region between India and Pakistan and spawned the genus Mus, the subgenus Mus, the species Mus musculus and several subspecies. This speciation was probably related to its migration, colonization and commensal relationship with humans. Thus, a characteristic that stands out in the mouse is its adaptive capacity and social flexibility, always seeking reproductive success through the provision of food, territorialism, and formation of small groups, usually polygamous. Thus, we can say that the mouse kept in its genetics characteristics of its wild behavior, such as competition and interpersonal aggressiveness, as well close relationship with humans and its high adaptability to new environments, provided mainly food supply. In conclusion, we believe that its welfare is directed towards respecting the natural characteristics and biological evolution of the mouse, for example, stress is part of the animal's physiology, its high adaptability and commensalism with humans. However, raising the welfare of mice in the house facilities should be accomplished by developing methodologies that enable the animal to demonstrate its preference (or choice) for space, food, floor, handling and other management procedures as animal reproduction or biological tests.
\end{abstract}

Keywords: Mouse; Welfare; Genealogy; Phylogeny

\section{State of the Art}

The mouse is an extremely interesting species. Its image has historically been associated with a plague (or pest) and a disease transmitter. Paradoxically, it has a high empathy for children, where we can find various entertainment products using the image of the mouse (toys, cartoons and others ...). However, his animal has a remarkable capacity for adaptation and survival that are extremely important for the discovery and treatment of diseases, especially for humans [1]. Currently, the number of publications indexed using the term "mouse" (or the keyword Mouse) on the PubMed (US National Library of Medicine Institutes of Health) website was 1.628, 275 publications, together with the "rat" (Rat $=1.690,355$ publications) the bio models with the highest number of scientific productions compared to other rodent species and lagomorph models:

a. Hamster (125.711 publications).

b. Guinea pig (149.049 publications)

c. Rabbits (348.520 publications) (Access: September 2019).

Highlight that the use of any animal species, including the mouse, is an activity that requires a thorough knowledge and study of ethical basis, in addition to the knowledge and with the legislation of each country, regarding the use of animals for purposes didactic and scientific [1]. In general, in all countries, the objective of 
applying ethical principles and legal regulation is primarily aimed at replacing animals with validated alternative methods that may replace their use. If this is not possible, the development of equipment, techniques and methodologies that can refine the use of animals should be emphasized, and all efforts should be related to the maintenance, promotion and elevation of animal welfare during biomedical assays [2]. In Brazil, our legal framework in the area of laboratory animal science, after 12 years in the National Congress, was the approval of Law $\mathrm{N}^{0} .11 .794$ [2]. Through this law the National Council for Control of Animal Experimentation (CONCEA) was structured on 2015 [2].

CONCEA Normative Resolution (RN) No 25 which describes the "General Introduction" chapter of the Brazilian Guide to the Production, Maintenance or Use of Animals for Teaching or Scientific Research Activities [3] and RN № 30 (2016), which establishes the Brazilian Directive for the Care and Use of Animals in Teaching or Scientific Research Activities (DBCA) which presents the principles and conducts that ensure the care and ethically correct management of animals produced, kept or used in teaching or scientific research activities in Brazil [4]. Finally, RN No 33 (2016), which proposes the chapter "Procedures - Rodents and Lagomorphs kept in facilities of educational or scientific research institutions" of the Brazilian Guide to the Production, Maintenance or Use of Animals in Animal Activities. Teaching or Scientific Research, in which it describes and guides animal welfare strategies in animal houses, such as care to consider for the welfare of rodents and lagomorphs $[3,4]$. In all this report, especially in $\mathrm{RN}^{\circ} \mathrm{N}^{\circ} 33$, we emphasize that the relationship between the performance of procedures and the welfare of rodents and lagomorphs, in our case highlighting the Mus musculus biomodel, imparts in certain sections that: "It is essential to know the biology of the species, race, lineage to work with, since the basic needs (physical, emotional or behavioral) to be met are not the same for all animals." and "... promote the expression of speciesspecific natural behaviors and a decrease, if not the disappearance, of abnormal behaviors.It should be based on promoting a positive effect on the physical and psychological welfare of the animal "[3].

We emphasize that the excerpts "to know species biology (physical, emotional or behavioral)" and "promote the expression of species-specific natural behaviors and a decrease, if not disappearance, of abnormal behaviors" were the motivating factors of this work [3]. Our aim was based on the question: How to know the physical, emotional or behavioral needs and the possibility of the expression of species-specific natural behaviors in order to provide the welfare of mice in the house facilities? Thus, we carry out a detailed bibliographic from the mouse origin of the species and its phylogeny, the knowledge about its geographical distribution, its habitat and natural behavior until the beginning of the controlled creation for the use in the scientific assays so that we can demonstrate, through scientific results, how we can approach the physical, emotional and behavioral needs of the space- restrain mouse in our animal house facilities and during biomedical trials by maintaining or enhancing animal welfare.

\section{Mouse: Origin of the Species}

Some authors state that there is a divergence in paleontological and phylogenetic studies regarding time estimates when dealing with lineage diversification rates, evolutionary patterns and historical biogeography, among other factors [5,6]. Fossil data is the most common type of paleontological calibration used to estimate the time period of the descendant in the phylogenetic tree. However, as described by Graur \& Martim [7], Dos Reis \& Yang [8] the incorporation of fossils for phylogenetic tree structuring can present difficulties such as:

i. The integrity of the fossil record

ii. The accuracy of the age of fossils

iii. The correction of the placement in the phylogenetic fossil calibration $[7,8]$

Kimura et al. [9] Describe that for a more reliable determination of time and fossil descendants may be the use of a methodology based on the study of the first upper molar teeth (M1). In this study the researchers used murine fossil specimens collected from northern Pakistan and examined by digitizing dental images and using tests such as Cochran-Mantel-Haenszel (CMH) and GoodmanKruskal's gamma [9]. The questions evaluated in the teeth were the change in frequency distribution of the size and inclination of the region called metacone in relation to paracone and the inclination of the respective axes [9]. However, [10] used a refined set of fossil calibrations that were used to reconstruct a murine family dated phylogeny using a multilocus dataset method (six nuclear and nine mitochondrial gene fragments) spanning 161 species and 82 murine genera from four existing subfamilies (Deomyinae, Gerbillinae, Lophiomyinae and Murinae) [10].

Therefore, regarding muridae family speciation, several types of genetic markers can be applied to peripheral populations:

i. C-band chromosomal patterns $[11,12]$.

ii. Several nuclear autosomal genes studied by protein electrophoresis or by RFLP DNA [13,14].

iii. Use of RFLP rDNA untranslated spacers [15].

iv. Immunoglobulins [16]

v. Satellite DNA [17].

vi. Antigens studied by serology [18].

vii. Some sequences of the Y chromosome [19] and mainly mitochondrial DNA [20].

The oldest known fossil murine, Antemus chinjiensis [9,21], was recorded in the region called Indo-Pakistan in the middle Miocene 14Ma (Millions of years ago), followed by Progonomys 
hussaini in the upper Miocene, which had a distribution including several regions in Asia, Europe and Africa. The Mus auctor, who represents the first specimen named Mus, also appeared in the subcontinent region of India and is also dated in the Miocene with about 5.5Ma [22]. From the specie M. auctor, the data suggest that there were several successive levels, with temporal proximity, of speciation events. The first level corresponds to the separation of the genus Mus from the other genres. This fact suggests that it occurred about 5 Ma where the genus Rattus, Apodemus, Nannomys (similar to fossils found in Africa 3Ma), Coelomys, Pyromys and Mus subgeneras such as M. cervicolor, M. cookii and M. caroli. The second level, not yet scientifically confirmed, suggests the division between the Indian branch of the genus Mus. This level of speciation refers to the separation between the Indian pygmy mice species as $M$. dunni and M. booduga (the so-called Leggada).

The third level corresponds to radiation from Asian species, which probably also occurred in India at approximately $2 \mathrm{Ma}$. The fourth radiation step is the separation around $1 \mathrm{Ma}$ of western paleartic species, which migrated west to east Asia (Mediterranean), North Africa and Southern Europe. Speciation of M. spicilegus and M. macedonicus clearly occurred very recently, but their ancestor diverged almost simultaneously from M. spretus and M. musculus subspecies. Finally, the fifth radiation level, corresponding to the individualization, around $0.5 \mathrm{Ma}$, of the main M. musculus subspecies, which probably originated from the Indian subcontinent, $M . m$. bactrianus, M. m. castaneus, M. m. musculus and M.m. domesticus [23].

\section{Geographic Distribution of Mus Musculus}

Through fossil studies (by various approaches), the most straightforward ancestor of the Mus genus is the Mus auctor, from the Progonomys class of origin in central Eurasia, mainly northeast India and Pakistan. Despite all the molecular, genetic and paleontological tools, it is very difficult to pinpoint the emergence and differentiation sites of existing species and subspecies. It is possible that the onset of subspecies division occurred during the expansion of India, however it is correct to state that radiation or geographic expansion of the M. musculus species occurred mainly through commensal behavior with humans [23]. According to biogeographic, genetic and archeozoological results, the $M$. musculus species has expanded from central Eurasia through two pathways, mainly according to human historical patterns. In the Middle East during the "Bronze Age" were found fossils of the genus Mus, but there are also records at the same time of fossils in other places such as central and northern Europe of this genus. This fact suggests that at least two routes were used by these animals to expand between Asia and Europe. Later, in the "Iron Age" we can infer that the species M. musculus colonized northwestern Europe $[23,24]$.
Through the study of mitochondrial DNA four subspecies of $M$. musculus were defined:

i. M. m. domesticus

ii. M. m. musculus

iii. M. m. castaneus

iv. M. m. bactrianus $[24,25]$

Mus musculus domesticus can be found in Western Europe, North Africa and the northern Mediterranean. It has the commensal habit but is capable of establishing wild populations. Mus musculus musculus presents its habitat between eastern Europe and northern Asia, is able to establish a permanent wild population where winter is mild and can be found as in Central Europe, where it forms with M. m. musculus a hybridization zone 30 to $40 \mathrm{~km}$ wide. Mus musculus castaneus is a subspecies of Southeast Asia but can be found in the eastern part of the Indian subcontinent throughout Southeast Asia. It is known for its interrelationship with M. m. musculus in China/Japan and has formed a hybrid population called M. m. molossinus. Finally, Mus musculus bactrianus can be found in southern Himalayas, in the mountain basins of Iran and northern India $[25,26]$.

\section{Habitat and Natural Behavior}

One of the main characteristics related to the habitat and natural behavior of the mouse is its commensal relationship with humans. But commensalism must be accepted as the only one theory [23]. In its origin, the genus Mus was related to arid climatic conditions (Eurasia - Indian Subcontinent), with low humidity and variable temperatures. However, during its evolutionary biology and speciation in Mus subgenus, we can observe a migration of Mus musculus subspecies to various regions, with different geographical and climatic conditions. Probably, this colonization factor of habitats with different characteristics can be considered as selective pressure factors for their speciation [27]. Potter in 1978 didactically suggested the division of the subgenus Mus as wild and the subspecies of M. musculus as commensal by their habitat type and the natural behavior of the animals, as described in Table 1 [28].

\begin{tabular}{|c|c|c|c|}
\hline \multicolumn{3}{|c|}{ Table 1: Habitat division between subgenus and subspecies. } \\
\hline Wild Habitat & $\begin{array}{c}\text { Geographic } \\
\text { Distribuition }\end{array}$ & $\begin{array}{c}\text { Commensal } \\
\text { Habitat }\end{array}$ & $\begin{array}{c}\text { Geographic } \\
\text { Distribuition }\end{array}$ \\
\hline M. cervicolor & India & M. m. domesticus & Europa \\
\hline M. macedonicus & Mediterrân & M.m. musculus & Europa \\
\hline M. spicelegus & Europa & M. m. molosssinus & China/Japan \\
\hline M.spretus & Mediterrâneo & M. m. casteneus & India \\
\hline & & M.m. bacitrianus & $\begin{array}{c}\text { Rússia/Afgha- } \\
\text { nistan }\end{array}$ \\
\hline
\end{tabular}


However as described by Sage in 1981, the static classification between subgenus/subspecies wild and commensals should be considered with prudence. Migration of the subgenus Mus (often associated with passive transport with humans) and colonization on several continents may have been an important component in the process of speciation of M. musculus subspecies and demonstrating a flexible relationship between species that maintain their wild or dinner habit. This flexibility would be primarily related to food supply, population density, territorialism and reproducibility. A wild species can become commensal, such as several species that have been domesticated for laboratory use while for example $M . m$. musculus, characterized as commensal, can become wild, competing with other species for territory and food [28]. This competition feature illustrates one of the key behaviors of the mouse in nature that is aggressiveness, especially from male $M$. m. domesticus. This aggressiveness is so imposing that this subspecies is able to dominate males M. m. musculus [29].

Aggressive behavior is a hereditary trait, with complex genetic, epigenetic and environmental determinism. In addition, aggressive behavior is likely to be subject to natural and sexual selection [30]. Variation in the intensity of aggressiveness between subspecies may be the result of environmental conditions (territory, food and reproduction). This fact highlights another striking feature in the natural behavior of mice that is adaptability and, more specifically, social flexibility and has been suggested as a possible explanation for their evolutionary success. It is suggested that the emergence of commensal behavior with humans occurred in the search for a safe environment and the supply of food, which is constantly being supplied, thus reducing competition between subspecies, predators and climate pressures [31]. Food disponibility promotes high population density, there is an organization of access to food (developing omnivorous habits with varied diets, including grains, seeds and insects) through a hierarchical population structure [27].

Territorialism remains, both in the wild and during the commensal habit, an important aspect for social organization. The hierarchy is mainly composed of a dominant and breeding male who exhales varying amounts of pheromones such as brevicomin (2,3-dehydro-exo-brevicomin) and thiazoline (2-sec-butyl-4,5dihydrothiazole) [32], few subordinate males and the remainder females. The group does not exceed 12 individuals. Behavioral observations have suggested that new individuals are not always readily integrated into the group, possibly due to genetic signaling expressed by pheromones, possibly due to caution in maintaining social cohesion. However, the integration of new individuals into the group can produce high genetic diversity, essentially due to extinctions in some situations of the dominant male reproductive. The acceptance of new group members, both male and female, has a successful trait when it induces genetic variability in the group. These animals, despite commensalism, have a very short life, rarely exceeding 7 months. Therefore, this rotation of individuals in the group can be considered beneficial for the maintenance of individuals and the genetic and evolutionary structure of mouse populations [23].

Interestingly, female mice prefer males who have higher levels of these pheromones [34]. Soini et al. [35], demonstrated that the absence of thiazoline in M. spicilegus, which is a non-commensal, wild species described as monogamous, presented aggression levels similar to M. m. domesticus. Therefore, low thiazoline levels may not explain the lower aggressiveness of M.m. musculus compared to M. m. domesticus [35]. However, low levels of brevicomin may be part of the explanation. In addition, M. m. musculus and $M$. spicilegus share much of their distribution in Southeast Asia and may have experienced similar selective pressures, resulting in part in convergent changes in their pheromone patterns, although similarities may also have evolved by chance [35]. In addition, the M. m. musculus have higher selectivity of mate selection when compared with M. m. domesticus. This low selectivity corroborates its promiscuous polygamous mating pattern. The high selectivity in M. m. musculus does not indicate that this subspecies is monogamous like M. spicilegus. Intermediate systems are believed to exist between these two extreme types of mating system promiscuity and monogamy - probably related to the genetics of each species or subspecies and the factors already described such as: habitat, nutritional availability and population density [36].

The relationship between the welfare of mice in the house facilities, their genealogy and natural behavior

The question that motivated this work was: "What would be the natural behavior of the mouse, especially the subspecies $M . m$. musculus in its habitat, considering from its origin? " The relevance of this question is primarily based on the national legislation and regulations where one can find the suggestion that the welfare of the mice is related to the possibility of providing during their maintenance in animal facilities for scientific and didactic use to express their natural behavior [1]. By conducting a thorough and detailed bibliographical survey on the genealogy, phylogeny and the few data on the natural or wild behavior of mice, we were able to delineate an interesting and complex set of remarkable characteristics of this animal, which can undoubtedly directly influence the welfare of mice under restricted space in animal houses. Several points drew our attention about this animal, such as its origin having occurred thousands of years ago, having come, where it can be studied from an ancestor that branched into several species, such as the rat, gerbil and others [9]. While the mouse in its pedigree continued to improve its characteristics, under intense forces of natural selection and with remarkable evolutionary success, it can be found in the most varied regions of the world, from desert to arctic environments, varying their subspecies, but maintaining its primordial genetic characteristics [23]. 
In our study we can point out some points that will be important to reflect on your welfare in animal houses:

i. We can consider these animals prepared physiologically for stress situations, especially the fight and flight system. It is important to maintain a routine and conditioning of management and procedures not to make stress harmful to the animal.

ii. They have a tremendous ability to adapt to harsh environments and conditions as long as there is time for them to adapt and maintain their routine.

iii. Commensal behavior with humans is extremely beneficial for the mouse. Initially for the supply of food, but we can also observe that although stealthy, the proximity to the human increases their social flexibility.

So, what we can say is that the relationship with humans was a path that these animals found given the ease of access to food and their ability to hide and escape risk situations. In addition, they are naturally non-isogenic animals with a natural control of variability and genetic perpetuation carried out through groups and the integration of new members to the group, mainly males and with high turnover, due to the low life expectancy of the dominant group. We may reflect that the welfare of this animal is much more tied to its own choices or preferences than when we try to relate our welfare state to that of this animal. Furthermore, we cannot compare our stress with the stress of this animal. It is an animal that already has a system, we can say, in stress. At this point, we believe that comes your ability to adapt. The suffering and discomfort of this animal start from the space restriction and its impossibility to move or seek a place of its choice (we believe more stable and safer). Therefore, we must look for ways to raise the welfare of this space-constrained animal so that its adaptation is close as possible to its preference and it is our obligation to maintain a routine and management always close to what the animal is adapted to avoiding the sudden changes as Ambiental variation in the house facilities.

We have learned from the genealogy of these animals several interesting features, such as their great strength and adaptability to selective pressures. His commensal relationship as a human being that completely changes his behavior, however, comes from his need for access to food, but we can say that his relationship with the human being does not cause suffering or stress to the mouse. So, to promote the welfare of mice in animal houses facilities, it is necessary to find out what is the animal's preference in all aspects, whether in cage size, group composition, floor type, room temperature, food offered, etc. These animals into stable conditions demonstrated adaptability and flexibility in the life routine. The natural behavior it's aggressive behavior. Groups formed after weaning form a fraternal relationship, decreasing the incidence of aggression in males in adulthood. Them can be consider that stress and discomfort will only occur disruption of its routine or its adaptability to the environment, even if in space restriction and if possible, no doubt offer elements that can encourage the animal to express your natural behavior such as foraging, sheltering or nesting through environmental enrichment.

\section{References}

1. Campos JDS, Demarque Kelly CristinaHoppe, Luanda Yanaan Fragoso, Viviane Muniz da SilvaMartins, Thais Veronez de Andrade et al., (2016) O comportamento do camundongo Swiss Webster em biotério de experimentação: Observações e reflexões. RESBCAL 4(1): 32-43.

2. BRASIL. Decreto no 6.899/2009 de 15 de julho. Diário Oficial [da] República Federativa do Brasil, Brasília, DF. Disponível em: < http:// www.planalto.gov.br/ccivil_03/_ato2007- 0/2009/decreto/d6899.htm > Acesso em 1 jul. 2019

3. BRASIL. Ministério da Ciência, Tecnologia e Inovação. Resolução Normativa no 30, de 02 de fevereiro de 2016a. Baixa a Diretriz Brasileira para o Cuidado e a Utilização de Animais em Atividades de Ensino ou de Pesquisa Científica - DBCA. Diário Oficial [da] República Federativa do Brasil, Brasília, DF, 3 fev. 2016. Disponível em: < http://www.mct.gov. br/upd_blob/0238/238684.pdf>. Acesso em 1 jul. 2019

4. CONCEA. Normativas do CONCEA para produção, manutenção ou utilização de animais em atividades de ensino ou pesquisa científica, Brasília.

5. Ho SYW, Phillips MJ (2009) Accounting for calibration uncertainty in phylogenetic estimation of evolutionary divergence times. Syst Biol 58(3): 367-380.

6. Ho SYW, Duchêne S (2014) Molecular-clock methods for estimating evolutionary rates and timescales. Mol Ecol 23(24): 5747-5965.

7. Graur D, Martin W (2004) Reading the entrails of chickens: molecular timescales of evolution and the illusion of precision. Trends Genet 20(2): 80-86.

8. Dos Reis M, Yang Z (2013) The unbearable uncertainty of Bayesian divergence time estimation. J Syst Evol 51(1): 30-43.

9. Kimura Y, Hawkins MT, McDonough MM, Jacobs LL, Flynn LJ (2015) Corrected placement of Mus-Rattus fossil calibration forces precision in the molecular tree of rodents. Sci Rep 28 (5):14444-14449.

10. Aghová T, Kimura Y, Bryja J, Dobigny G, Granjon L, et al. (2018) Fossils know it best:Using new set of fossil calibrations to improve the te mporal phylogenetic framework of murid rodents (Rodentia: Muridae) Mol Phylogenet Evol (128): 98-111.

11. Moriwaki K, Miyashita N, Suzuki H, Kurihara Y, Yonekawa H (1986) Genetic features of major geographical isolates of Mus musculus. Curr Top Microbial Immunol 127: 55-61.

12. Moriwaki K, Miyashita N, Yonekawa H (1985) Genetic survey of the origin of laboratory mice and its implication in genetic monitoring. In the Contribution of Laboratory Animal Science to the Welfare of Man and A nimals, edn. J Archibold, J Ditchfield, HC ROwsell, pp. 237-247.

13. Sage RD (1981) Wild mice. Evol Theor7(81): 39-90.

14. Watanabe T, Miyashita N, Moriwaki K, Hilgers J (1987) Evolutionary relationships between laboratory mice and subspecies of Mus musculus based on the genetic study of pancreatic proteinase loci, Prt- I, Prt-2, Prt3 and Prt-6. Biochem Genet 25 (3-4): 239-251.

15. Suzuki H, Miyashita N, Moriwaki K, Kominami R, Muramatsu M, et al. (1986) Evolutionary implication of heterogeneity of the nontranscribed spacer region of ribosomal DNA repeating units in various subspecies of Mus musculus. Mol Bioi Evol 3(2): 126-137.

16. Riblet R, Tutter A (1989) Evolution of the immunoglobulin heavy chain variable region (lgh-V) locus in the genus Mus. Immunogenetics 30(1): 315-329.

17. Redi CA, Garagna S, Della Valle G, Bottiroli G, Dell'Orto P, et al. (1990) Differences in the organization and chromosomal allocation of satellite 
DNA between the European long tailed house mice Mus domesticus and Mus musculus. Chromosoma 99(1): 11-17.

18. Robinson PI, Steinmetz M, Moriwaki K, Fisher Lindahl K (1984) Beta-2 microglobulin types in mice of wild origin. Immunogenetics 20(6): 655665.

19. Tucker PK, Lee BK, Lundrigan BL, Eicher EM (1992) Geographic origin of the Y chromosomes in "old" inbred strains of mice. Mamm Genome 3(5): 254-261.

20. Yonekawa H, Moriwaki K, Gotoh 0, Watanabe J, Hayashi J-I, et al. (1980) Relationship between laboratory mice and the subspecies Mus Musculus domesticus based on restriction endonuclease cleavage patterns of mitochondrial DNA. lpn Genet 55(4): 289-296.

21. Jacobs LL (1977) A new genus of murid rodent from the miocene of Pakistan and comments on the origin of the Muridae. Paleo Bios 25: $1-11$.

22. Jacobs LL, Downs WR (1994) The evolution of murine rodents in Asia. Natl Sci Museum Monogr 8: 149-156.

23. Boursot P, Aujfrai JC, Britton Davidian J, Bonhomme F (1993) The evolution of house mice Annu. Rev Ecol Syst 24:119-152.

24. Capanna E (1982) Robertsonian numerical variation in anima speciation: Mus musculus, an emblematic model. Prog Clin Biol Res 96: 155-177.

25. Din W, Anand R, Boursot P, Darviche D, Jouvin Marche E, et al. (1993) Origin and radiation of the house mouse. I Clues from nuclear genes Evolution 12: 36-39.

26. Searle JL (1991) A hybrid zone comprising staggered chromosomal clines in the house mouse (Mus musculus domestjcus). Proc Biol Sci 246(1315): 47-52.
27. Phifer Rixey M, Nachman MW (2015) Insights into mammalian biology from the wild house mouse Mus musculus. Elife p. 4.

28. Morse HC (1978) Origins of inbred mice. Academic Press Inc. New York.

29. Dureje L, Bímová BV, Piálek J (2011) No postnatal maternal effect on male aggressiveness in wild-derived strains of house mice. Aggress Behav 37(1): 48-55.

30. Canastar A, Maxson SC (2003) Sexual aggression in mice: effects of male strain and of female estrous state. Behav Genet 33(5): 521-528.

31. Sutherland DR, Spencer PB, Singleton GR, Taylor AC (2005) Kin interactions and changing social structure during a population outbreak of feral house mice. Mol Ecol 14(9): 2803-2814.

32. Cavaggioni A, Mucignat Caretta C, Redaelli M, Zagotto G (2006) The scent of urine spots of male mice, Mus musculus: Changes in chemical composition over time. Rapid Commun Mass Spectrom 20(24): 37413746

33. Jemiolo B, Gubernick DJ, Catherine Yoder M, Novotny M (1994) Chemical characterization of urinary volatile compounds of Peromyscus californicus, a monogamous biparental rodent. J Chem Ecol 20(10): 2489-2500.

34. Soini HA, Wiesler D, Koyama S, Féron C, Baudoin C, et al. (2009) Comparison of urinary scents of two related mouse species, Mus spicilegus and Mus domesticus. J Chem Ecol 35(5): 580-589.

35. Frynta D, Volfová R, Franková Nováková M, Stejskal V (2010) Oestrous females investigate the unfamiliar male more than the familiar male in both commensal and non-commensal populations of house mice. Behav Processes 83(1): 54-60. 